\title{
Total somatic symptom score as a predictor of health outcome in somatic symptom disorders ${ }^{\dagger}$
}

Barbara Tomenson, Cecilia Essau, Frank Jacobi, Karl Heinz Ladwig, Kari Ann Leiknes, Roselind Lieb, Gunther Meinlschmidt, John McBeth, Judith Rosmalen, Winfried Rief, Athula Sumathipala and Francis Creed on behalf of EURASMUS Population Based Study Group

\section{Background}

The diagnosis of somatisation disorder in DSM-IV was based on 'medically unexplained' symptoms, which is unsatisfactory.

\section{Aims}

To determine the value of a total somatic symptom score as a predictor of health status and healthcare use after adjustment for anxiety, depression and general medical illness.

\section{Method}

Data from nine population-based studies (total $n=28377$ ) were analysed.

\section{Results}

In all cross-sectional analyses total somatic symptom score was associated with health status and healthcare use after adjustment for confounders. In two prospective studies total somatic symptom score predicted subsequent health status. This association appeared stronger than that for medically unexplained symptoms.

\section{Conclusions}

Total somatic symptom score provides a predictor of health status and healthcare use over and above the effects of anxiety, depression and general medical illnesses.

\section{Declaration of interest}

F.C. has been a member of the American Psychiatric Association DSM-5 work group on somatic distress disorders and he and A.S. are members of the World Health Organization ICD-11 working group on the classification of somatic distress and dissociative disorders.
The diagnosis of somatisation disorder in DSM-IV ${ }^{1}$ is based on numerous 'medically unexplained' symptoms but this diagnosis has been criticised as the measurement of medically unexplained symptoms is unreliable and the concept is inherently dualistic. ${ }^{2,3}$ These difficulties, together with measurement problems, have meant that many population-based surveys have omitted somatoform disorders, and healthcare planners have tended to ignore these disorders. ${ }^{4}$ By contrast, clinical studies have used a checklist of all somatic symptoms and found that total somatic symptom score correlates well with the outcomes of impaired function and medical help-seeking even after adjustment for mental disorders. $^{5-7}$ The current project examined whether these relationships are similar in population-based samples, which are free of any bias related to treatment-seeking. The study aimed to determine whether the associations between somatic symptom score, health status and healthcare use remain after adjustment for important confounders including depression, anxiety and the presence or absence of a medical condition. If so, this would help to determine the value of total somatic symptom score as a clinically useful predictor over and above the presence or absence of depression, anxiety and medical conditions. The present study concerned secondary analysis of data collected in populationbased studies and was more comprehensive than previous studies as it included potential key confounders. ${ }^{7-10}$ We hypothesised that total somatic symptom score contributes further to the association with, or prediction of, impairment or healthcare use beyond that of the most important confounders including depression, anxiety and the presence or absence of a medical condition. If this hypothesis is supported this strengthens the validity of syndromes or disorders based on somatic symptom presentations. The study had two secondary aims: (a) to compare total somatic symptom score with medically unexplained symptoms and (b) to examine

'See editorial, pp. 320-321, this issue. the effect on outcome of numerous somatic symptoms when this is accompanied by additional health concerns and health anxiety. This combination of burdensome somatic symptoms and other psychological features form part of the diagnostic criteria of DSM-5 'somatic symptom disorder.'

\section{Method}

Data came from nine population-based studies (total $n=28377$ ). Details are shown in Table 1. The sites were chosen as their samples were all reasonably large, they had used recognised instruments, the investigators were willing and able to send their data to Manchester for analysis (seven sites did so) or they were prepared to analyse their own data in an identical way. The Manchester statistician (B.T.) supplied Oslo and Munich (Early Developmental Stages of Psychopathology (EDSP) study) with SPSS syntax files and excel file templates to this end.

\section{Measurement of somatic symptoms}

Five sites used a self-administered questionnaire asking respondents to mark those somatic symptoms that they found bothersome. Two sites each used the Patient Health Questionnaire (PHQ-15) ${ }^{5}$ (Marburg $^{16,17}$ and Sri Lanka ${ }^{22}$ ) and the Zerssen scale ${ }^{23}$ (Munich $^{20}$ and Dresden ${ }^{19}$ ); one used the Symptom Checklist-90Revised (SCL-90-R) ${ }^{24}$ somatisation subscale $\left(\right.$ Bremen $\left.^{12}\right)$ and one site used the Somatic Symptom Inventory (SSI) ${ }^{25}$ (Manchester ${ }^{10}$ ) (Table 1). Four sites used the Composite International Diagnostic Interview (CIDI), ${ }^{26}$ which allowed direct comparison between medically unexplained and total number of somatic symptoms (Dreseden, ${ }^{19}$ Munich (EDSP study), ${ }^{13-15}$ Groningen, ${ }^{21}$ Oslo ${ }^{18}$ ).

We omitted gender-specific (for example painful menstruation) and depression-related items (for example impaired sleep) prior to the creation of a total somatic symptom score. For the self-rated 
Table 1 Participating sites ${ }^{a}$

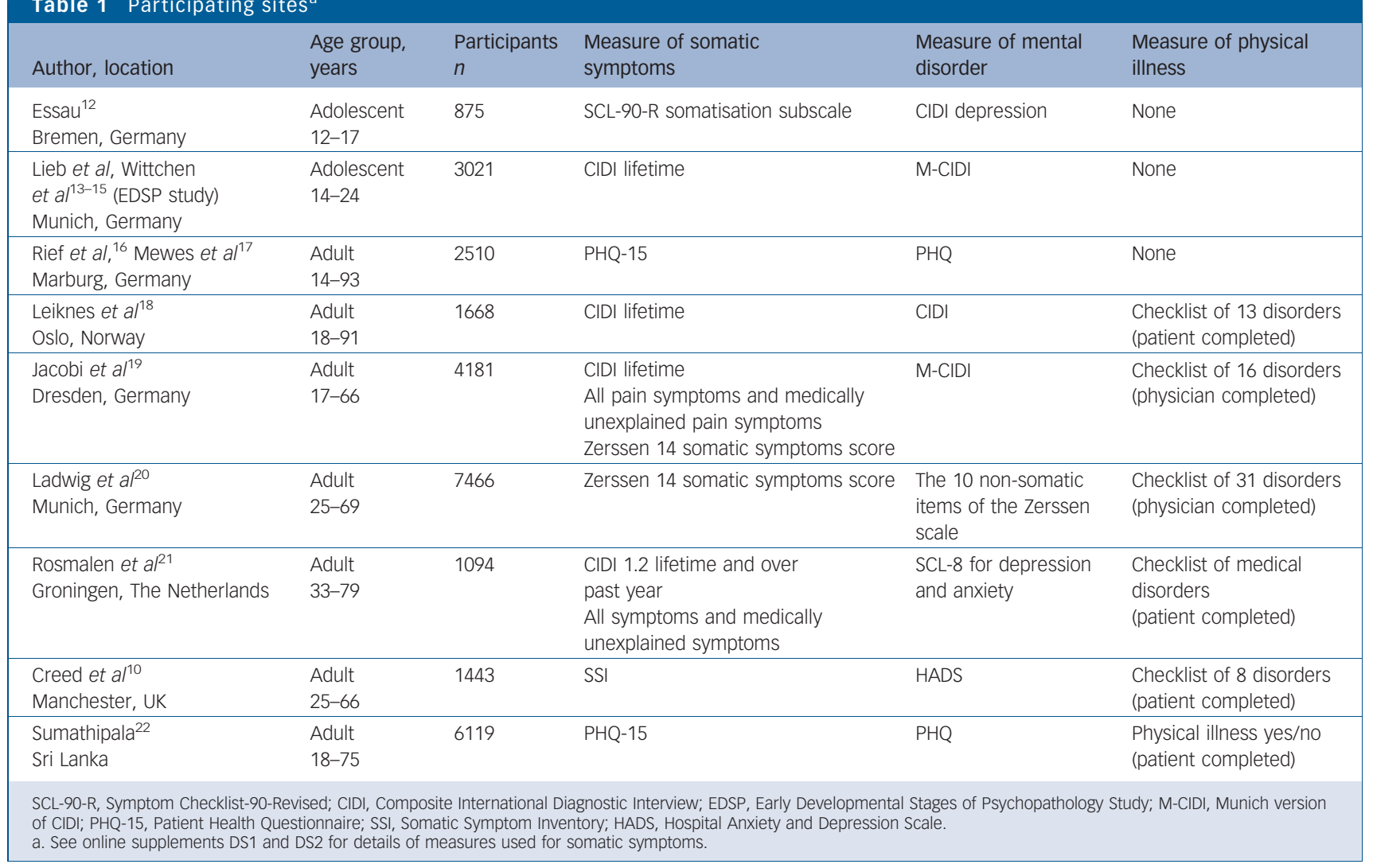

questionnaires total somatic symptom score reflected both the number of somatic symptoms and their severity (how bothersome they were). As these symptoms were rated on a three- or fourpoint scale of severity, their scores ranged as follows: SCL-90-R somatisation items (0-48), PHQ-12 (after removal of genderspecific and depression-related items: 0-24), Zerssen (0-42), SSI (13-52). For the CIDI, after excluding four female-specific items, we agreed a list of 37 somatic symptoms, each of which was rated as present or absent (irrespective of whether they were clinically significant, the effect of drug intake or as a result of a medical condition). Thus, for the CIDI total symptom score was a simple symptom count. For the secondary analysis we examined separately those symptoms that were not fully explainable by a medical condition or have not always been caused by the intake of any substances. These are defined on the CIDI as those symptoms that are 'clinically significant' (indicated either by seeking help from a medical doctor or other mental health professional, repeated intake of medication or significant distress and interference with daily life because of the symptom) and for which no underlying physical illness had been diagnosed by the doctor and which have not always been the effect of drug intake (such symptoms form the basis of the CIDI diagnostic algorithm for DSM-IV somatoform disorders).

\section{Outcome measures}

Health status was measured at four sites using the Short Form Health Survey (SF-36 or SF-12) ${ }^{27}$ physical and mental health component summary scores or the EQ-5D. ${ }^{28}$ At other sites individual questions were used (online Table DS1). Healthcare use was measured at all but two sites. It was measured retrospectively except at one site, where it was also measured prospectively (online Table DS2).

\section{Covariates}

Anxiety and depressive diagnoses or measures of anxiety or depressive symptoms were recorded at all sites (five sites used the CIDI, two used PHQ- ${ }^{29}$ depression and PHQ-7 anxiety (or 'GAD-7'), ${ }^{30}$ one used the Hospital Anxiety and Depression Scale $(\mathrm{HADS})^{31}$ and one the Zerssen psychological items). General medical illnesses had been measured at four sites using selfadministered checklists, by a doctor in Dresden ${ }^{19}$ and Munich (Ladwig et al) ${ }^{20}$ and by a single question in Sri Lanka. ${ }^{22}$ At six sites we were able to use a core set of covariates in the multivariate analyses: age, gender, anxiety, depression and general medical illness. At three sites there was no measure of general medical illness (Table 2).

At one site only (Manchester) ${ }^{10}$ we assessed the proportion of participants who fulfilled the criteria of numerous somatic symptoms, concerns about seriousness of symptoms and marked health anxiety (criteria A and B of DSM-5 somatic symptom disorder). For this purpose we identified those in the top 20\% of SSI scores (this corresponds to six somatic symptoms that bothered the respondent quite a bit or worse), and who worried 'quite a bit' or 'a great deal' (a) about there being something seriously wrong with their body and (b) about their health.

\section{Statistical analysis}

In order to demonstrate the distribution of scores in the populations, data are presented in graphical form as a frequency/density plot of total symptom scores (and for medically unexplained symptoms), split by gender, anxiety, depression or physical illnesses.

In order to establish the variables that were correlated with total somatic symptom score at each site we used multiple regression analysis with total somatic symptom score as the dependent variable. 
The independent variables were: age, gender, anxiety, depression (all sites) and number of general medical illnesses (six sites only). Unstandardised regression coefficients are presented.

In order to test the main hypothesis, we used multivariable analysis to assess the association between somatic symptom score (as an independent variable) and health status and healthcare use (as dependent variables). The following potential confounders were included as independent variables: age, gender, anxiety, depression, general medical disorders (if available) and any other relevant confounders (listed in column 3 in Tables DS1 and DS2). We used multiple regression analysis for continuous dependent variables, logistic regression for dichotomous dependent variables and negative binomial regression when the dependent variable was a number of visits to the doctor. At two sites, no health status or healthcare use data were available. Results presented are standardised regression coefficients for multiple regression analyses, odds ratios per standard deviation for logistic regression or incidence rate ratios per standard deviation for negative binomial regression. This allowed direct comparison of coefficients for total symptom score and medically unexplained symptoms score; the significance of any difference between these was assessed using the stata test command.

To compare total somatic symptom score, number of medically unexplained symptoms and anxiety/depression score as predictors of health status, we used data from Groningen. ${ }^{21}$ We performed receiver operating characteristic (ROC) curve analyses to compare each of these as predictors of five EQ-5D subscales at a 2-year follow-up.
Using data from Manchester ${ }^{10}$ we identified participants with high SSI scores and marked worry about the seriousness of their symptoms and marked health anxiety as defined above. We compared the physical and mental summary scores of SF-12 and the thermometer measure of EQ-5D for this group with the remainder of the participants using ANCOVA to adjust for age, gender, number of general medical illnesses and HADS score. Analyses were carried out in SPSS version 16 or 19, and Stata version 11 on Windows.

\section{Results}

\section{Total somatic symptom score in the population}

The most common somatic symptoms reported were: back, joint, head and abdominal pains and pain in the extremities. These were reported by $11-77 \%$ of respondents on most measures. By contrast, medically unexplained somatic symptoms were reported by $11 \%$ or fewer of respondents (online supplements DS1 and DS2).

At all sites the somatic symptom score was distributed as a positively skewed continuous distribution. This was true for total somatic symptom score (Fig. 1) and for medically unexplained symptoms only (Figs 2(c) and 2(d)). The curve is moved to the right in women and for participants who had anxiety or depressive disorder or general medical illnesses (Fig. 1). This effect of anxiety, depressive or general medical disorders is similar for total somatic

Table 2 Correlates of somatic symptom scores using multiple regression ${ }^{a}$

\begin{tabular}{|c|c|c|c|c|}
\hline Author, location & Age group & Instrument & $\begin{array}{l}\text { Recent or lifetime } \\
\text { symptoms }\end{array}$ & Significant correlates of somatic symptoms score \\
\hline \multicolumn{5}{|c|}{ Studies that assessed MUS and total somatic symptom score using CIDI } \\
\hline $\begin{array}{l}\text { Lieb et al, Wittchen } \\
\text { et al }{ }^{13-15} \text { (EDSP study) } \\
\text { Munich, Germany }\end{array}$ & Adolescent & M-CIDI lifetime & $\begin{array}{l}\text { All lifetime } \\
\text { symptoms }\end{array}$ & $\begin{array}{l}\text { Age }(b=0.09 \text { per year), female }(b=0.47) \text {, anxiety }(b=1.75) \text {, depression } \\
(b=1.62) \text {. No measure of physical illness available }\end{array}$ \\
\hline $\begin{array}{l}\text { Leiknes et a/ }{ }^{18} \\
\text { Oslo, Norway }\end{array}$ & Adult & CIDI lifetime & $\begin{array}{l}\text { All lifetime } \\
\text { symptoms }\end{array}$ & $\begin{array}{l}\text { Female ( } b=0.87) \text {, severe physical illnesses (out of } 13)(b=0.95) \text {, anxiety } \\
\text { and/or depression }(b=2.32) \text {. Age not significant }\end{array}$ \\
\hline $\begin{array}{l}\text { Rosmalen et } a^{21} \\
\text { Groningen, The Netherlands }\end{array}$ & Adult & Lifetime CIDI 1.2 & $\begin{array}{l}\text { All lifetime } \\
\text { symptoms }\end{array}$ & $\begin{array}{l}\text { Age }(b=-0.04) \text {, female }(b=1.48) \text {, number of physical illnesses }(b=2.29) \text {, } \\
\text { any CIDI diagnosis, major depressive disorder, panic or generalised } \\
\text { anxiety disorder }(b=2.87)\end{array}$ \\
\hline $\begin{array}{l}\text { Jacobi et al }{ }^{19} \\
\text { Dresden, Germany }\end{array}$ & Adult & $\begin{array}{l}\text { M-CIDI somatic } \\
\text { symptoms }\end{array}$ & $\begin{array}{l}\text { All lifetime pain } \\
\text { symptoms }\end{array}$ & $\begin{array}{l}\text { Age }(b=-0.01) \text {, female }(b=0.21) \text {, physical illnesses }(b=0.40) \text {, major } \\
\text { depressive disorder }(b=0.41) \text {, anxiety disorder }(b=0.51)\end{array}$ \\
\hline \multicolumn{5}{|c|}{ Studies that assessed total somatic symptom score using questionnaires } \\
\hline $\begin{array}{l}\text { Essau }^{12} \\
\text { Bremen, Germany }\end{array}$ & Adolescent & $\begin{array}{l}\text { SCL-90-R } \\
\text { somatisation } \\
\text { subscale }\end{array}$ & Recent & $\begin{array}{l}\text { Female }(b=1.57) \text {, major depressive disorder }(b=2.80){ }^{b} \text { No measure } \\
\text { of physical illness available }\end{array}$ \\
\hline $\begin{array}{l}\text { Rief et al, }{ }^{16} \text { Mewes et al }{ }^{17} \\
\text { Marburg, Germany }\end{array}$ & Adult & PHQ-15 ${ }^{\mathrm{C}}$ & Recent & $\begin{array}{l}\text { Age }(b=0.02 \text { per year), female }(b=0.29) \text {, anxiety }(b=0.52) \text {, depression } \\
(b=0.24) \text {. No measure of physical illness available }\end{array}$ \\
\hline $\begin{array}{l}\text { Jacobi et al } \\
\text { Dresden, Germany }\end{array}$ & Adult & $\begin{array}{l}\text { Zerssen } 14 \\
\text { somatic symptoms } \\
\text { score }\end{array}$ & Recent & $\begin{array}{l}\text { Age }(b=0.08 \text { per year), female }(b=1.24) \text {, physical illnesses }(b=2.14) \text {, } \\
\text { major depressive disorder }(b=2.14) \text {, anxiety disorder }(b=3.52) \text {, panic } \\
\text { disorder }(b=2.18)\end{array}$ \\
\hline $\begin{array}{l}\text { Ladwig et al20 } \\
\text { Munich, Germany }\end{array}$ & Adult & $\begin{array}{l}\text { Zerssen } 14 \\
\text { somatic symptoms } \\
\text { score }\end{array}$ & Recent & $\begin{array}{l}\text { Age }(b=0.03 \text { per year), female }(b=0.60) \text {, physical illnesses }(b=0.58 \\
\text { per diagnosis), Zerssen 'depression' }(b=1.00)\end{array}$ \\
\hline $\begin{array}{l}\text { Creed et al }{ }^{10} \\
\text { Manchester, UK } \\
\text { Sumathipala22 } \\
\text { Sri Lanka }\end{array}$ & Adult & SSI score only & Recent & $\begin{array}{l}\text { Female }(b=1.12) \text {, physical illnesses }(b=3.05 \text { per illness), HADS anxiety } \\
\text { score }(b=0.49) \text {, HADS depression score }(b=0.62) \text {. Age not significant } \\
\text { Age }(b=0.02 \text { per year), female }(b=0.58) \text {, physical illnesses yes } / \text { no } \\
(b=1.45) \text {, PHQ-7 anxiety score }(b=-0.05) \text {, PHQ- } 9 \text { depression score } \\
(b=0.41)\end{array}$ \\
\hline \multicolumn{5}{|c|}{$\begin{array}{l}\text { MUS, medically unexplained symptoms; EDSP, Early Developmental Stages of Psychopathology Study; M-CIDI, Munich version of Composite International Diagnostic Interview; } \\
\text { CIDI, Composite International Diagnostic Interview; SCL-90-R, Symptom Checklist-90-Revised; PHQ, Patient Health Questionnaire; SSI, Somatic Symptom Inventory; HADS, Hospital } \\
\text { Anxiety and Depression scale. } \\
\text { a. The dependent variable was the relevant measure of somatic symptoms used at each site. The independent variables were age, gender, anxiety, depression and general medical } \\
\text { illness, where available. Figures are the unstandardised regression coefficient, b, for each correlate. } \\
\text { b. Only included adolescents aged } 12-17 \text { years. No measure of physical illness was available. Only depression was entered as a psychiatric diagnosis, since anxiety was only } \\
\text { reported by one participant, who also had depression. } \\
\text { c. The PHQ-15 excluding two depression items and one female-only item. }\end{array}$} \\
\hline
\end{tabular}


(a)
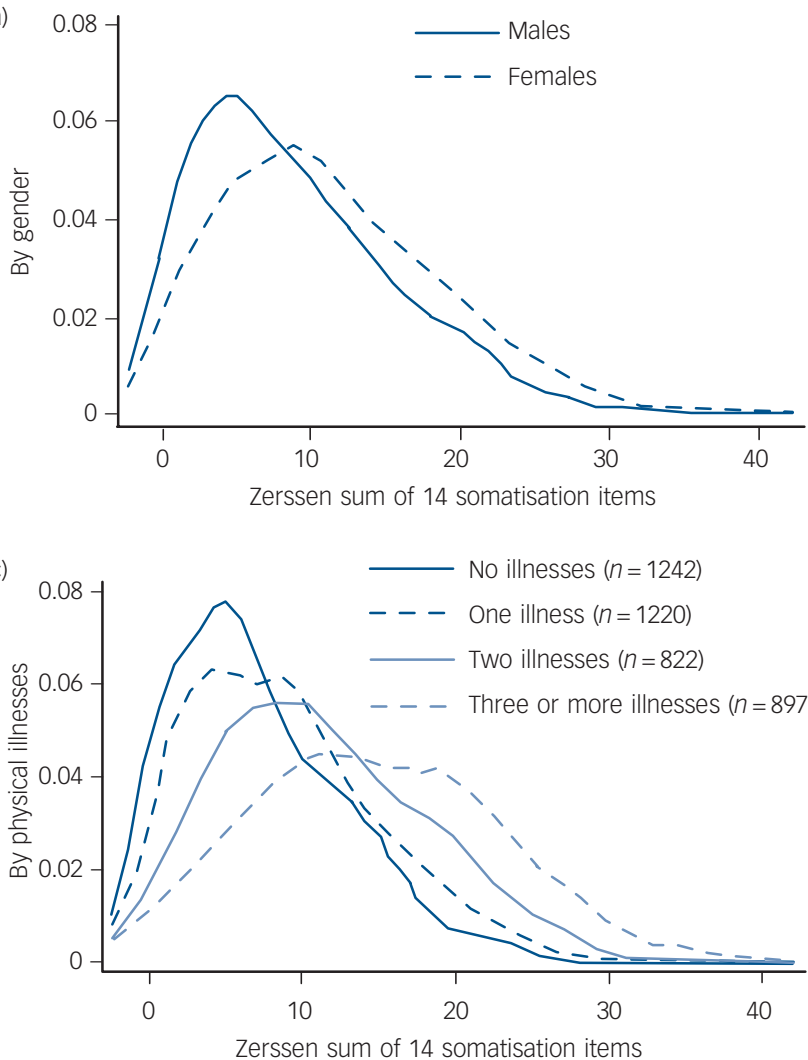

(b)

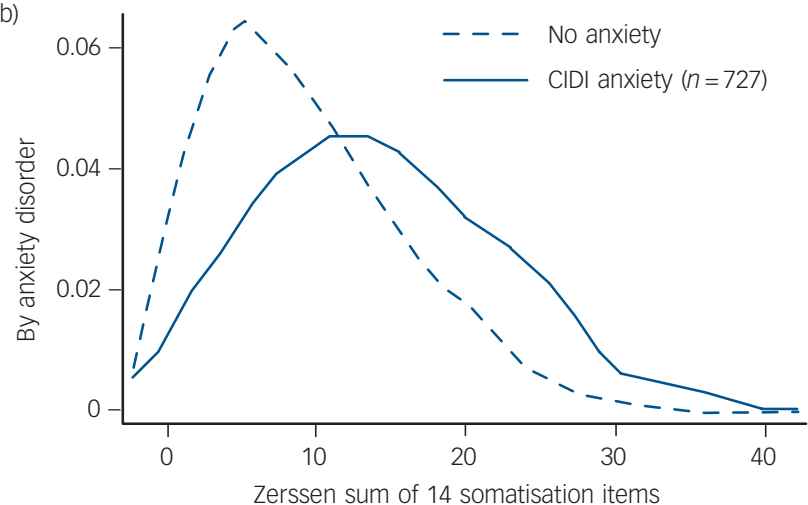

(d)

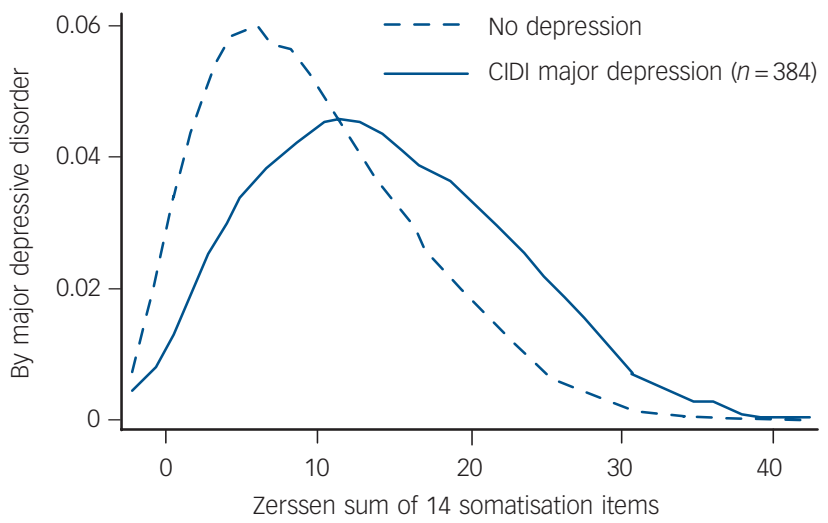

Fig. 1 Dresden data: probability density plots for Zerssen somatic symptom scores by (a) gender, (b) anxiety disorder, (c) number of physical illnesses and (d) major depressive disorder.

CIDI, Composite International Diagnostic Interview.

symptom score (Figs 2(a) and (b)) and for medically unexplained symptoms (Figs 2(c) and (d)).

\section{Correlates of total somatic symptom score}

The correlates of total somatic symptom score for each site are shown in Table 2. At all sites female gender, anxiety, depression and general medical illnesses (where measured) were significantly correlated with a higher somatic symptom score. Older age was associated with increased number of somatic symptoms at five sites.

\section{Total somatic symptom score and health status}

After adjustment for age, gender, anxiety/depression, general medical illness (where available), and other relevant covariates, total somatic symptom score was a correlate of health status at all seven sites where this was assessed (Table DS1). Five of these analyses were cross-sectional, but at the two sites with prospective data (Groningen ${ }^{21}$ and Manchester ${ }^{10}$ ) baseline total somatic symptom score predicted subsequent health status (1-2 years later) after adjustment for confounders.

\section{Total somatic symptom score and healthcare use}

In all five cross-sectional analyses, where relevant data were available, total somatic symptom score was significantly correlated with (retrospectively reported) healthcare use after adjustment for confounders (Table DS2). In one prospective study (Manchester ${ }^{10}$ ), baseline total somatic symptom score (SSI) was correlated with retrospective, but not prospective, healthcare use.

\section{Comparison of total somatic symptom score and medically unexplained symptoms}

At the four sites where we could analyse both, the correlates of number of medically unexplained symptoms were similar to those shown for total somatic symptom score (Table 2, further details available from the authors on request).

For the four sites where data were available (Table DS1) the association with health status, after adjustment for confounders, was stronger for total somatic symptom score than for number of medically unexplained symptoms. This difference was significant for Munich (EDSP study) ${ }^{13-15}(P=0.006)$ Oslo $^{18}(P<0.001)$; and Dresden $^{19}(P<0.001$ for SF-36 physical but not SF-36 mental component score) and Groningen ${ }^{21}$ (mobility $(P=0.044)$, selfcare $(P=0.002)$, usual activities $(P<0.001)$ and pain/discomfort $(P=0.007))$.

The prospective data from Groningen ${ }^{21}$ indicated also that total somatic symptom score was a more accurate predictor of follow-up EQ-5D scores than the number of medically unexplained symptoms (Table 3). For the four EQ-5D subscales except anxiety/depression, the area under the curve (AUC) was significantly greater for total symptom score $(\mathrm{AUC}=0.76-0.84)$ than for medically unexplained symptoms (AUC $=0.61-0.69$ ).

\section{Outcome when both numerous somatic symptoms and additional health concerns and anxiety are present}

The data from Manchester ${ }^{10}$ showed that the participants who had a high total somatic symptom score (SSI score of 26 or more) and who also expressed concerns about the seriousness of their bodily symptoms and marked health anxiety ( $n=23,2.5 \%$ of the sample) had more impaired health status than participants who had a low 
(a)

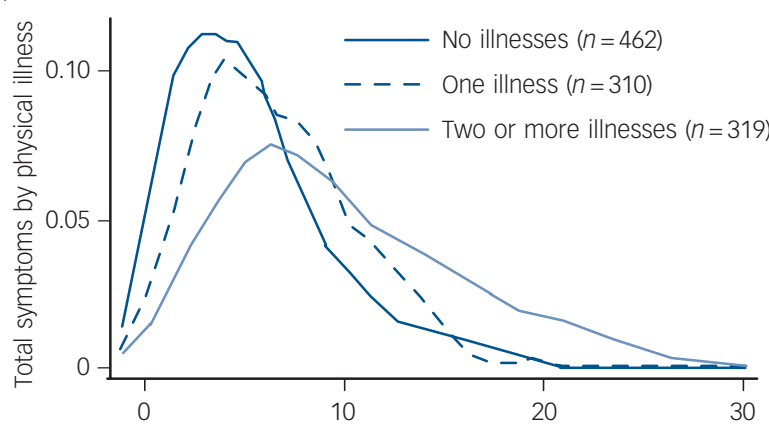

(c)

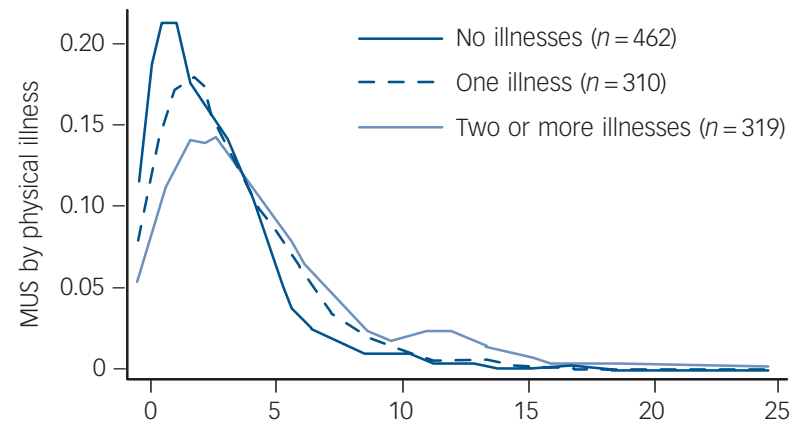

(b)

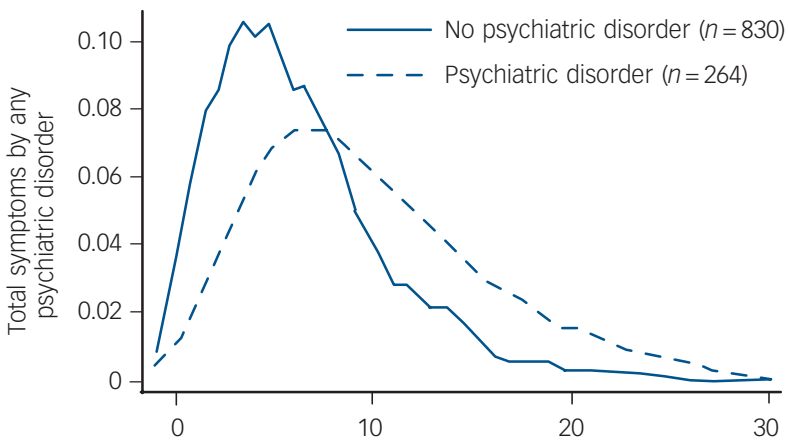

(d)

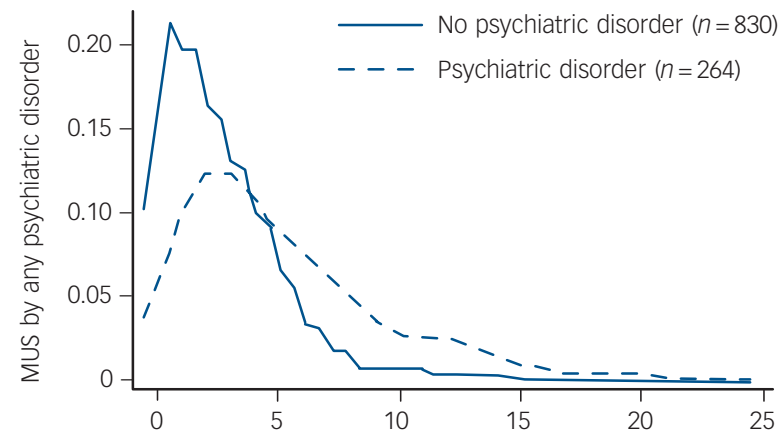

Fig. 2 Groningen data: probability density plots for lifetime (a) total symptoms by number of physical illnesses, (b) total symptoms by number of psychiatric disorders, (c) medically unexplained symptoms (MUS) only by number of physical illnesses and (d) medically unexplained symptoms only by number of any psychiatric disorders.

Psychiatric disorder: major depressive disorder, generalised anxiety or panic disorder.

total somatic symptom score or a high total somatic symptom score without the additional psychological features (Table 4).

\section{Discussion}

\section{Main findings}

This study has two new important findings. First, whichever somatic symptom measure was used, total somatic symptom score was associated with female gender, anxiety, depression and general medical illness at all sites where these were measured. Second, and most importantly, after adjustment for these confounders, total somatic symptom score was associated with health status and healthcare use in cross-sectional analyses and predicted health status in the two prospective studies. Furthermore, our results suggest strongly that the association with (physical) health status and healthcare use was somewhat stronger for total somatic symptom score than for number of medically unexplained symptoms alone. We were able to test, at one site only, whether outcome is impaired most markedly when a high total somatic symptom score was accompanied by high health anxiety and marked concern about the seriousness of bodily symptoms, and found this to be the case.

\section{Strengths and limitations}

The study has strengths and limitations that must be recognised. One of the main limitations of this study is the variety of instruments used at the different sites, which meant that we were not able to combine the results from different sites or make exact comparisons between sites. Another limitation was that, at most sites, we had only a checklist of medical illnesses completed by the respondent and we did not have a measure of severity of general medical illnesses. Only at two sites were the medical diagnoses verified by a doctor. We found that general medical illness was an important confounder of the association between

\begin{tabular}{|c|c|c|c|c|c|}
\hline & \multicolumn{5}{|c|}{ EQ-5D scores } \\
\hline & Mobility & Self-care & Usual activities & Pain/discomfort & Anxiety/depression \\
\hline Total somatic symptom score, AUC ( $95 \%$ Cl) & $0.76(0.73-0.80)$ & $0.84(0.78-0.89)$ & $0.77(0.73-0.81)$ & $0.77(0.74-0.80)$ & $0.68(0.63-0.72)$ \\
\hline Number of MUS, AUC (95\% Cl) & $0.62(0.57-0.67)$ & $0.61(0.49-0.73)$ & $0.67(0.62-0.72)$ & $0.69(0.65-0.72)$ & $0.67(0.62-0.71)$ \\
\hline $\begin{array}{l}\text { Difference between AUC for total somatic } \\
\text { symptom score and AUC for MUS, } P\end{array}$ & $<0.001$ & $<0.001$ & 0.002 & $<0.001$ & 0.76 \\
\hline Symptom Checklist (SCL-8) score, AUC (95\% Cl) & $0.60(0.55-0.65)$ & $0.73(0.65-0.82)$ & $0.71(0.67-0.75)$ & $0.64(0.61-0.68)$ & $0.82(0.78-0.85)$ \\
\hline
\end{tabular}




\begin{tabular}{|c|c|c|c|c|c|}
\hline & \multicolumn{4}{|c|}{ Mean $(95 \% \mathrm{Cl})$} & \multirow[b]{2}{*}{$\begin{array}{c}\text { Adjusted } \\
P\end{array}$} \\
\hline & $\begin{array}{l}\text { SSI }<26 \\
(n=737)\end{array}$ & $\begin{array}{l}\mathrm{SSI} \geqslant 26 \text { but without health } \\
\text { anxiety or marked concerns } \\
\text { that something seriously } \\
\text { wrong with body ( } n=138)\end{array}$ & $\begin{array}{l}\mathrm{SSI} \geqslant 26 \text { with either health } \\
\text { anxiety or marked concerns } \\
\text { that something seriously } \\
\text { wrong with body }(n=27)\end{array}$ & $\begin{array}{l}\mathrm{SSI} \geqslant 26 \text { and both health } \\
\text { anxiety and marked concerns } \\
\text { that something seriously } \\
\text { wrong with body }(n=23)\end{array}$ & \\
\hline EQ-5D thermometer & $81.34(80.4-82.3)$ & $77.4(75.3-79.7)$ & $72.0(67.0-76.9)$ & $61.0(55.5-66.6)^{b}$ & $<0.001$ \\
\hline SF-12 physical component score & $52.2(51.6-52.7)$ & $47.1(45.8-48.4)$ & $44.5(41.6-47.5)$ & $36.9(33.6-40.3)^{b}$ & $<0.001$ \\
\hline SF-12 mental component score ${ }^{c}$ & $50.0(49.3-50.7)$ & $42.5(40.9-44.2)$ & $37.4(33.6-41.1)$ & $34.0(29.8-38.3)^{b}$ & $<0.001$ \\
\hline \multicolumn{6}{|c|}{$\begin{array}{l}\text { SSI, Somatic Symptom Inventory. } \\
\text { a. The EQ-5D thermometer and Short Form Health Survey (SF-12) physical and mental component scores for groups with a high total somatic symptom score with or without health } \\
\text { anxiety and marked concerns that something is seriously wrong with body. Scores adjusted for age, gender, total number of physical illnesses and Hospital Anxiety and Depression Scale. } \\
\text { b. Health status significantly reduced for patients with SSI } \geqslant 26 \text { and both health anxiety and marked concerns that something seriously wrong with body more than for the two intermediate } \\
\text { groups, SSI } 26 \text { and only one or neither of health anxiety and marked concerns that something seriously wrong with body. (Bonferroni corrections were made for multiple pair-wise } \\
\text { group comparisons). } \\
\text { c. Hospital Anxiety and Depression Scale total score excluded as covariate in view of high correlation with SF-12 mental component score. }\end{array}$} \\
\hline
\end{tabular}

number of somatic symptoms and outcome, accounting for a proportion of the variance similar to that of depression or anxiety. It is possible that severity of general medical illness might have accounted for a greater proportion of the variance; this has been inadequately considered in most previous studies. The inclusion of a single site from a different culture (Sri Lanka) ${ }^{22}$ is also a limitation; a greater number of sites from different cultures would be necessary before making any observation about the relationship between variables across different cultures.

On the other hand, the similarity of the results across sites, even though different measures were used, might be regarded as a strength as well as a limitation, as it suggests greater generalisability of the findings. This variation also applies to the measures of covariates (anxiety, depressive and general medical disorders), which differed at the different sites. More prospective studies are required as somatic symptoms have been excluded from many large-scale epidemiological studies, in spite of the high frequency of somatoform disorders in population studies. ${ }^{4,8,32,33}$

The total number of participants in this study (total $n=28377$ ) makes this the largest study of its kind and the samples were all population based, thus removing the possibility of bias from treatment-seeking and weighting towards patients with mental health concerns, which is a limitation of primary care studies in the area. ${ }^{34}$

\section{Explanation for our findings}

There is a very close relationship between number of somatic symptoms, anxiety/depression and general medical illness. The number of somatic symptoms in chronic general medical illness increases with anxiety and depression ${ }^{35}$ but we have shown in this study that somatic symptoms, number of reported general medical illnesses and anxiety/depression are all independent correlates of health status. It is known that numerous somatic symptoms predict a poor outcome of depressive disorder ${ }^{36}$ and a poor outcome of medical disorders. ${ }^{37}$ In this study we have shown that this negative impact of numerous somatic symptoms on outcome is a general one found in studies at several different sites, even after adjustment for confounders.

The association between total somatic symptom score and health status may have been stronger than that for medically unexplained symptoms because total somatic symptom score includes a measure of how bothersome each symptom is regarded to be by the respondent. This leads to a larger spread of scores and, in addition, includes a dimension of emotional response associated with the somatic symptom, which may add to the predictive value of the measure. This explanation cannot explain the difference between CIDI total symptom score and CIDI medically unexplained symptoms (Table DS1), as both were simple symptom scores.

There has been one previous large study of primary care attenders that demonstrated that the association between numerous somatic symptoms and impaired health status occurred with both medically explained and medically unexplained somatic symptoms; the association was strongest for people with both types of somatic symptoms. ${ }^{6,38}$ One clinic study has shown that the pattern of association between number of somatic symptoms and health status and healthcare costs was very similar whether the presenting symptoms were medically explained or unexplained. ${ }^{37,39}$ This association has been demonstrated recently in cancer and sickle cell disease, where it may be impossible to distinguish explained and unexplained somatic symptoms. ${ }^{40,41}$ Our study demonstrated that even medically unexplained symptoms are associated with general medical illness. Such findings suggest that the adverse effect on outcome of multiple bothersome somatic symptoms may affect all patients whether or not they have general medical illnesses. This moves away from the view that patients with medically unexplained symptoms are a separate group; a fact that has been recognised in the DSM-5 somatic symptom disorder diagnostic category. ${ }^{3}$

\section{Implications}

Diagnostic concepts in mental health disciplines may not be separated by natural boundaries but many have high clinical utility as they provide useful information concerning outcome, aetiology and treatment response. ${ }^{42}$ Within this framework, our findings are important in identifying total somatic symptom score as a predictor or correlate of outcome (health status and healthcare use), independent of anxiety, depression and general medical illnesses. Thus, somatic symptoms cannot be regarded as primarily a reflection of concurrent anxiety and depression. ${ }^{43}$ Indeed, there is some evidence that the number of somatic symptoms is a predictor of treatment response in depression as well as other conditions. ${ }^{44-46}$ Our findings support the validity of a separate dimension based on numerous bothersome somatic symptoms that could be a useful measure in clinical or epidemiological studies aimed at predicting health status. A diagnostic category, such as that in DSM-5, that includes distressing somatic symptoms as one criterion, should have greater clinical utility than one based on medically unexplained somatic symptoms.

Further prospective studies are needed to replicate the results presented here that total somatic symptom score is a predictor of subsequent health status and to determine whether this does indeed predict subsequent healthcare use. From the data presented 
here it seems likely that a short questionnaire measuring bothersome somatic symptoms might be used in large-scale population-based studies to clarify the true importance of somatic symptoms as a predictor of outcome. ${ }^{10}$

The analysis of data from a single site in this study suggests that the presence of certain psychological features (criteria B of the new DSM-5 diagnosis) as well as numerous bothersome symptoms describes a group with greater impairment of health status. However, this result is limited by small numbers.

In sum, these findings are important in view of the changes to the diagnostic criteria for DSM-5 somatic symptom disorder, which move away from 'medically unexplained symptoms' as the core diagnostic feature to 'any severely distressing somatic symptoms. ${ }^{3}$

\section{Barbara Tomenson, MSC, Biostatistics Unit, Institute of Population Health, University of Manchester, UK: Cecilia Essau, PhD, Department of Psychology, Whitelands of Manchester, UK; Cecilia Essau, PhD, Department of Psychology, Whitelands
college, University of Roehampton, London, UK; Frank Jacobi, PhD, Technische Universität Dresden, Germany; Karl Heinz Ladwig, PhD, Institute of Epidemiology ॥, Helmholtz Zentrum München, German Research Centre for Environmental Health, Neuherberg, Germany; Kari Ann Leiknes, MD, PhD, Norwegian Knowledge Centre for the Health Services, Oslo, Norway; Roselind Lieb, PhD, Division of Clinical Psychology and Epidemiology, Department of Psychology, University of Basel, Switzerland; Gunther Meinlschmidt, PhD, Division of Clinical Psychology and Epidemiology, Department of Psychology, University of Basel, Switzerland, and Research Department of Psychobiology, Psychosomatics and Psychotherapy, Clinic of Psychosomatic Medicine and Psychotherapy, LWL University Hospital \& Faculty of Medicine, Ruhr University Bochum, Germany; John McBeth, PhD, Arthritis Research UK Primary Care Centre, Keele University, UK; Judith Rosmalen, PhD, University of Groningen, University Medical Center Groningen, Interdisciplinary Center Psychopathology and Emotion Regulation, Groningen, The Netherlands; winfried Rief, PhD, Depatment of Clinical Psychology, Univity of Marbus; Winfried Rief, $P$ D, Department of Clinica Psychology, Un, The Netherity Germany; Athula Sumathipala, MD, PhD, King's College London, UK; Francis Creed, FMedSci, Institute of Brain, Behaviour and Mental Health, University of Manchester, UK}

Correspondence: Barbara Tomenson, Biostatistics Unit, Institute of Population Health, University of Manchester, Jean McFarlane Building (3rd Floor), Oxford Road, Manchester M13 9PL, UK. Email: barbara.tomenson@manchester.ac.uK

First received 3 May 2012, final revision 22 Apr 2013, accepted 8 May 2013

\section{Funding}

The American Psychiatric Association funded this study. The original studies, whose data have been used in this paper were funded by: German Federal Ministry of Research, Education and Science, BMBF, Deutsche Forschungsgemeinschaft (DFG), Netherland Organisation for Scientific Research (NOW), Norwegian Research Council, UK Medical Research council.

\section{References}

1 American Psychiatric Association. Diagnostic and Statistical Manual of Mental Disorders (4th edn) (DSM-IV). APA, 1994.

2 Creed $F$, Guthrie $E$, Fink $P$, Henningsen $P$, Rief W, Sharpe $M$, et al. Is there a better term than "medically unexplained symptoms"? J Psychosom Res 2010; 68: 5-8.

3 Dimsdale J, Creed FH. The proposed diagnosis of somatic symptom disorders in DSM-5 to replace somatoform disorders in DSM-IV-a preliminary report. J Psychosom Res 2009; 66: 473-6.

4 Creed F. Should general psychiatry ignore somatization and hypochondriasis? World Psychiatry 2006; 5: 146-50.

5 Kroenke K, Spitzer RL, Williams JB. The PHQ-15: validity of a new measure for evaluating the severity of somatic symptoms. Psychosom Med 2002; 64: 258-66.

6 Kisely S, Goldberg D, Simon G. A comparison between somatic symptoms with and without clear organic cause: results of an international study. Psychol Med 1997; 27: 1011-9.

7 Barsky AJ, Orav EJ, Bates DW. Somatization increases medical utilization and costs independent of psychiatric and medical comorbidity. Arch Gen Psychiatry 2005; 62: 903-10.

8 Lieb R, Meinlschmidt G, Araya R. Epidemiology of the association between somatoform disorders and anxiety and depressive disorders: an update. Psychosom Med 2007; 69: 860-3.

9 Ladwig KH, Marten-Mittag B, Lacruz ME, Henningsen P, Creed F. Screening for multiple somatic complaints in a population-based survey: does excessive symptom reporting capture the concept of somatic symptom disorders? Findings from the MONICA-KORA Cohort Study. J Psychosom Res 2010; 68: 427-37.

10 Creed FH, Davies I, Jackson J, Littlewood A, Chew-Graham C, Tomenson B, et al. The epidemiology of multiple somatic symptoms. I Psychosom Res 2012; 72: 311-7.

11 American Psychiatric Association. Diagnostic and Statistical Manual of Mental Disorders (5th edn) (DSM-5). APA, 2013.

12 Essau CA. Course and outcome of somatoform disorders in non-referred adolescents. Psychosomatics 2007; 48: 502-9.

13 Lieb R, Zimmermann $\mathrm{P}$, Friis RH, Hofler M, Tholen S, Wittchen HU. The natural course of DSM-IV somatoform disorders and syndromes among adolescents and young adults: a prospective-longitudinal community study. Eur Psychiatry 2002; 17: 321-31.

14 Wittchen $\mathrm{H}$, Perkonigg A, Lachner G, Nelson CB. Early Developmental Stages of Psychopathology Study (EDSP): objectives and design. Eur Addict Res 1998; 4: 18-27.

15 Lieb R, Isensee B, von Sydow K, Wittchen HU. The Early Developmental Stages of Psychopathology Study (EDSP): a methodological update. Eur Addict Res 2000; 6: 170-82.

16 Rief W, Mewes R, Martin A, Glaesmer H, Brähler E. Evaluating new proposals for the psychiatric classification of patients with multiple somatic symptoms. Psychosom Med 2011; 73: 760-8.

17 Mewes R, Rief W, Brahler E, Martin A, Glaesmer H. Lower decision threshold for doctor visits as a predictor of health care use in somatoform disorders and in the general population. Gen Hosp Psychiatry 2008; 30: 349-55.

18 Leiknes KA, Finset A, Moum T. Commonalities and differences between the diagnostic groups: current somatoform disorders, anxiety, depression and musculoskeletal disorders. J Psychosom Res 2010; 68: 439-46.

19 Jacobi F, Wittchen $\mathrm{H}-\mathrm{U}$, Müller N, Hölting C, Sommer S, Lieb R, et al. Estimating the prevalence of mental and somatic disorders in the community: aims and methods of the German National Health Interview and Examination Survey. Int J Methods Psychiatr Res 2002; 11: 1-19.

20 Ladwig KH, Marten-Mittag B, Formanek B, Dammann G. Gender differences of symptom reporting and medical health care utilization in the German population. Eur J Epidemiol 2000; 16: 511-8.

21 Rosmalen JGM, Tak LM, de Jonge P. Empirical foundations for the diagnosis of somatization: implications for DSM-5. Psychol Med 2011; 41: 1133-42.

22 Sumathipala A. National Survey on Mental Health in Sri Lanka: Final Research Report. Institute of Research and Development, 2007.

23 Zerssen D. Die Beschwerde-Liste Klinische Selbstbeurteilungsfragebögen aus dem Münchner Psychiatrischen Informationszentrum [List of Clinical Complaints: Self-Rating Questionnaires from the Munich Centre for Psychiatric Research]. Beltz, 1976.

24 Derogatis LR. SCL-90-R: Administration, Scoring, and Procedures Manual for The Revised Version. Johns Hopkins University School of Medicine, 1997.

25 Derogatis LR, Lipman RS, Rickels K, Uhlenhuth EH, Covi L. The Hopkins Symptom Checklist (HSCL): a self-report symptom inventory. Behav Sci 1974; 19: 1-15.

26 Wittchen $\mathrm{H}-\mathrm{U}$. Reliability and validity studies of the WHO Composite International Diagnostic Interview (CIDI): a critical review. J Psychiatr Res 1994; 28: 57-84.

27 Gandek B, Ware JE, Aaronson NK, Apolone G, Bjorner JB, Brazier JE, et al. Cross-validation of item selection and scoring for the SF-12 Health Survey in nine countries: results from the IQOLA Project. International Quality of Life Assessment. J Clin Epidemiol 1998; 51: 1171-8.

28 Williams A. Euroqol - a new facility for the measurement of health-related quality-of-life. Health Policy 1990; 16: 199-208.

29 Kroenke K, Spitzer RL, Williams JB. The PHQ-9: validity of a brief depression severity measure. J Gen Intern Med 2001; 16: 606-13.

30 Spitzer RL, Kroenke K, Williams JBW, Lowe B. A brief measure for assessing generalized anxiety disorder - the GAD-7. Arch Intern Med 2006; 166 : 1092-7.

31 Zigmond AS, Snaith RP. The Hospital Anxiety and Depression Scale. Acta Psychiatr Scand 1983; 67: 361-70

32 Wittchen $\mathrm{H}-\mathrm{U}$, Jacobi F. Size and burden of mental disorders in Europe - a critical review and appraisal of 27 studies. Eur Neuropsychopharmacol 2005; 15: $357-76$.

33 Creed $\mathrm{FH}$, Barsky A. A systematic review of somatisation and hypochondriasis. J Psychosom Res 2004; 56: 391-408.

34 Üstün TB, Sartorius N. Mental Illness in General Health Care. An International Study. Wiley, 1996. 
35 Katon W, Lin EHB, Kroenke K. The association of depression and anxiety with medical symptom burden in patients with chronic medical illness. Gen Hosp Psychiatry 2007; 29: 147-55.

36 Huijbregts KML, van der Feltz-Cornelis C, van Marwijk HWJ, de Jong FJ, van der Windt DAWM, Beekman ATF. Negative association of concomitant physical symptoms with the course of major depressive disorder: a systematic review. J Psychosom Res 2010; 68: 511-9.

37 Creed F. The relationship between somatic symptoms, health anxiety, and outcome in medical out-patients. Psychiatr Clin North Am 2011; 34: 545-64.

38 Kisely S, Goldberg D, Simon G. A comparison between somatic symptoms with and without clear organic cause: results of an international study. Psychol Med 1997; 27: 1011-9.

39 Jackson J, Fiddler M, Kapur N, Wells A, Tomenson B, Creed F. Number of bodily symptoms predicts outcome more accurately than health anxiety in patients attending neurology, cardiology, and gastroenterology clinics. J Psychosom Res 2006; 60: 357-63.

40 Kroenke K, Zhong X, Theobald D, Wu JW, Tu WZ, Carpenter JS. Somatic symptoms in patients with cancer experiencing pain or depression prevalence, disability, and health care use. Arch Intern Med 2010; 170: 1686-94.
41 Sogutlu A, Levenson JL, McClish DK, Rosef SD, Smith WR. Somatic symptom burden in adults with sickle cell disease predicts pain, depression, anxiety, health care utilization, and quality of life: the PiSCES Project. Psychosomatics 2011; 52: 272-9.

42 Kendell $\mathrm{R}$, Jablensky A. Distinguishing between the validity and utility of psychiatric diagnoses. Am J Psychiatry 2003; 160: 4-12.

43 Mayou R, Kirmayer L, Simon G, Kroenke K, Sharpe M. Somatoform disorders: time for a new approach in DSM-V. Am J Psychiatry 2005; 162: 847-55.

44 Klengel T, Heck A, Pfister H, Brückl T, Hennings JM, Menke A, et al. Somatization in major depression - clinical features and genetic associations. Acta Psychiatr Scand 2011; 124: 317-28.

45 Nickel R, Egle UT, Rompe J, Eysel P, Hoffmann So. Somatisation predicts the outcome of treatment in patients with low back pain. J Bone Joint Surg $\mathrm{Br}$ 2002; 84B: 189-95.

46 Creed F, Tomenson B, Guthrie E, Ratcliffe J, Fernandes L, Read N, et al. The relationship between somatisation and outcome in patients with severe irritable bowel syndrome. J Psychosom Res 2008; 64: 613-20.

\section{psychiatry and sacred texts}

\section{The prophet Samuel, hypnagogic hallucinations and the voice of God}

\author{
Christopher C. H. Cook
}

The Hebrew book known as Samuel, written originally by an anonymous author in perhaps the 6th century BCE, gives an account (1 Samuel 3:1-14) of how Samuel, as a young person, first hears the voice of God. Laying down to sleep one night in the temple at Shiloh, where he is an attendant supporting the work of the elderly priest, Eli, Samuel hears his name called out loud and assumes that it is Eli who has called him. This happens three times before Eli concludes that God is calling Samuel, and he gives the boy instructions to respond to the voice, if he hears it again, with the words 'Speak, your servant is listening'. When Samuel responds to the voice as instructed, there follows an account of a longer message that he receives from God concerning the punishment that God will impose upon Eli and his family, because Eli did not restrain his sons from blasphemy. This inaugurates a prophetic vocation that Samuel exercises from then on.

While some prophets in ancient Israel (e.g. Hosea, Elisha, Jeremiah) are accused of madness by their peers, and others (e.g. Ezekiel) have been diagnosed as mentally ill by some modern commentators, it is interesting that neither fate seems to befal Samuel. Hearing a voice when falling asleep, a form of hypnagogic hallucination commonly experienced in the genera population, is not usually considered diagnostic of mental illness, and hearing one's name called is a typical example. The subsequent longer message that Samuel receives is described by some commentators as a dream theophany, and by others as a vision, but it would be unusual to identify such a complex monologue as a part of a psychopathological experience. Lack of psychiatric attention to this text may therefore be due to lack of evidence for psychopathology.

Importantly for Jews, Christians and others who read Samuel as a sacred text, the purpose of the author was not to provide an historical account of ancient psychiatric phenomenology, and we therefore have no unambiguous evidence as to whether Samuel's experiences were hallucinatory or in a dream. This does not matter, for it is the prophetic message, and the narrative account of God's dealings with Samuel and Eli, that scripture is concerned with, not diagnosis. However, the possibility that Samuel experienced hypnagogic hallucinations is not incompatible with a belief that he heard God through them. It is the interpretation of the narrative and the experience, the meaning that is found in them, and the ways in which they enrich (or deplete) the lives of those concerned (Samuel, Eli, or the readers of the text) that confer value on them, not a scientific account of how they occurred. 